\title{
"La corte de los Milagros". La infancia callejera en la ciudad de México a finales de los años treinta.
}

\section{ZOILA SANTIAGO ANTONIO.}

Cita:

ZOILA SANTIAGO ANTONIO (2021). "La corte de los Milagros". La infancia callejera en la ciudad de México a finales de los años treinta. Sociedad e infancias, 5, 145-157.

Dirección estable: https://www.aacademica.org/zoila.santiago/8 ARK: https://n2t.net/ark:/13683/pr42/vyn

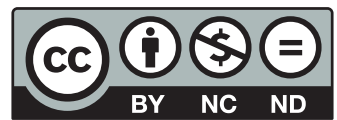




\title{
Sociedad e Infancias
}

ISSN-e 2531-0720

\section{"La Corte de los Milagros". La infancia callejera en la ciudad de México a finales de los años treinta}

\author{
Zoila Santiago Antonio ${ }^{1}$
}

Recibido: 4 de enero de 2020 / Aceptado: 23 de noviembre de 2020

Resumen. El objetivo del texto es analizar la movilidad de los niños y jóvenes por la ciudad de México a finales de la década de 1930, de cómo se apropiaron de los espacios públicos para vivir su infancia. Y darnos cuenta de que la infancia que vivieron los sectores medios y altos de la sociedad fue distinta de los sectores populares, para ellos, los límites entre el trabajo y la diversión no existieron, todo lo contrario, en su ir y venir por la ciudad de México, combinaron sus actividades laborales y de recreación. Ellos al igual que los adultos tuvieron que hacer frente a la criminalización y marginación de sus actividades. Por otro lado, a partir del análisis de las fuentes, lo que encontramos es una ausencia de la infancia femenina callejera, a diferencia de los varones, a ellas las encontramos en los espacios privados. Al final, el texto busca acercar al lector a esas diferentes infancias que se vivieron en la ciudad de México.

Palabras clave: Infancia callejera; trabajo infantil; pobreza; criminalidad y diversión.

\section{[pt] “A Corte dos Milagres”. Infância de rua na Cidade do México no final dos anos 30}

Resumo. O objetivo do texto é analisar a mobilidade de crianças e jovens através da Cidade do México, no final da década de 1930 , de como eles se apropriaram de espaços públicos para viver sua infância. A partir do texto, perceberemos que a infância que viveu os setores médio e alto da sociedade era diferente dos setores populares; para eles, os limites entre trabalho e diversão não existiam exatamente o oposto, no seu ir e vir. A Cidade do México combinou suas atividades de trabalho e recreação. Eles, como adultos, tiveram que enfrentar a criminalização e a marginalização de suas atividades. Por outro lado, a partir da análise das fontes, o que encontramos é a ausência da infância feminina de rua, diferentemente dos homens, eles são encontrados em espaços privados. No final, o texto procura aproximar o leitor das diferentes infâncias vividas na Cidade do México.

Palavras chave: Infância de rua; trabalho infantil; pobreza; crime e diversão.

\section{[en] "The Court of Miracles". Street Childhood in Mexico City in the late Thirties}

Abstract. The aim of this article is to analyze the mobility of children and young people through Mexico City in the late 1930s, how they appropriated public spaces to live their childhood. From the text we will realize that the childhood that lived the middle and upper class sectors of society was different from the popular sectors, for the last the limits between work and fun did not exist quite the opposite, in their coming and going by Mexico City combined their work and recreation activities. They, like adults, had to face the criminalization and marginalization of their activities. On the other hand, from the analysis of the documents, what we find is an absence of street female childhood; unlike boys, they are found in private spaces. In the end, the text seeks to bring the reader closer to those different childhoods that were lived in Mexico City.

Keywords: Street childhood; child labor; poverty; crime and fun.

Sumario. 1. Introducción. 2. Una ciudad ruidosa. 3. Movilidad de los niños y niñas en la ciudad. 4. Ubicación geográfica del hogar de los niños y niñas. 5. Niños y jóvenes trabajando. 6. La calle: entre el trabajo, el ocio y la criminalidad. 7. Reflexiones finales. 8. Referencias bibliográficas.

Cómo citar: Santiago Antonio, Z. (2021): "La Corte de los Milagros”. La infancia callejera en la ciudad de México a finales de los años treinta, Sociedad e Infancias, 5, número especial, 145-157.

\footnotetext{
Licenciada, maestra y doctoranda en Historia por la Universidad Autónoma Metropolitana-Iztapalapa. Línea de investigación: historia social de la infancia y el Tribunal para Menores del Distrito Federal. Este texto se realizó gracias al apoyo otorgado por el Programa de las Becas Posdoctorales en Cuerpos Académicos Consolidados y en Consolidación de la Dirección General de Educación Superior Universitaria de la Secretaría de Educación Pública y bajo la supervisión de la Doctora Lourdes Herrera Feria, responsable del CA-142 de la Benemérita Universidad Autónoma de Puebla (México).
}

E-mail: zoilasan09@gmail.com 


\section{Introducción}

En los últimos años, los investigadores de la historia de la infancia han señalado la ausencia de estudios que analizan, por un lado, las experiencias y prácticas infantiles y por el otro lado, las representaciones sobre la infancia (Sosenski y Jackson, 2012: 7-8). De tal forma, pretendemos darle voz a un pequeño grupo de niños que por cuestiones del azar o de la vida pisaron el Tribunal para Menores Infractores entre 1939 y 1940. El objetivo de este texto es analizar cómo los niños y jóvenes de los sectores populares se apropiaron de la calle y de los espacios públicos de la ciudad de México entre esos años. Para tal objetivo nos centramos en las noticias proporcionadas por la prensa, en este caso, de los periódicos El Excelsior, El Universal y El Nacional para informarnos de las reglamentaciones, campañas e instituciones que aparecieron con el fin de resguardar a la infancia callejera. Asimismo, recurrimos a algunas historias de los niños y jóvenes que fueron presentados al Tribunal para Menores durante estos años para dar cuenta de los usos de estos espacios. Y rescatamos algunos pasajes de la obra del antropólogo Óscar Lewis, Los hijos de los Sánchez y las memorias de Ramón Beteta publicadas en su libro Jarano.

Los expedientes del Tribunal para Menores Infractores nos permiten acercarnos no sólo a la vida de los niños y jóvenes que pisaron el establecimiento, sino también adentrarnos en su vida familiar, escolar o laboral. Esta información se encuentra recopilada en el examen social que los delegados investigadores ${ }^{2}$ practicaban, el examen tenía como objetivo averiguar todo lo relacionado con ellos, desde su nivel de estudios hasta sus antecedentes familiares o laborales, para determinar si el motivo de la infracción cometida había sido por cuestiones sociales. Es así como nos encontramos con pequeños relatos de su vida cotidiana. Arlette Farge dice que el archivo es "el bosquejo de un acontecimiento inesperado", "enfocado sobre algunos instantes de la vida de personajes ordinarios" que "describe con palabras de todos los días lo irrisorio y lo trágico en el mismo tono" (Farge, 1991: 11). Y es precisamente lo que encontramos en dichos documentos y describiremos en las siguientes líneas.

El ubicar a los niños y jóvenes en las calles, de describir sus andanzas en los centros urbanos no es algo nuevo; por el momento podemos mencionar tres trabajos que nos han inspirado a continuar en esta línea. Dos de estos trabajos no están relacionados con el periodo propuesto en este artículo, ni con la ciudad de México, pero los hemos seleccionado porque encontramos ciertas similitudes con el ir y venir de los niños y los jóvenes que fueron presentados en el Tribunal. El primer trabajo es del historiador Óscar Reyes Ruvalcaba, quien explica como la infancia tapatía hizo suyos los espacios urbanos durante el porfiriato (Reyes, Ó., 2007: 119). A partir de relatos de novelas, memorias, autobiografías, planos, mapas de la ciudad y fotografías explica este proceso, para él la apropiación de la ciudad implicó "un proceso de aprendizaje, durante el cual los menores van afinando determinada forma de ver, leer y otorgar significado" de tal forma, se apropiaron y transformaron la ciudad (Reyes, Ó., 2007: 119-122). Y es lo que observamos para el caso de la ciudad de México, para estos niños y jóvenes las calles significaron lugares de esparcimiento, convivencia y trabajo. Pero, al mismo tiempo que las calles se convirtieron en una estrategia de sobrevivencia, porque les permitía imbuirse en el mundo laboral y con su trabajo ayudar en sus hogares, también era un lugar donde podían refugiarse cuando habían sido abandonados o porque simplemente les gustaba vivir solos. Sin embargo, eso ocasionó que estuvieran en constante contacto con las autoridades y, por lo tanto, había una mayor posibilidad de ingresar al Tribunal para Menores Infractores. Así que, mientras los niños concibieron la ciudad y sus calles como una zona "segura" que les ofrecía la oportunidad de trabajar, divertirse, pasear o dormir en algún de rincón de ella, las autoridades percibieron estos espacios de forma diferente.

Por otro lado, Susana Sosenski aborda la relación de los niños y la calle en la ciudad de México durante la década de 1930, a partir de artículos publicados en la prensa y de los expedientes del Tribunal para Menores analiza cómo los adultos y menores percibieron la calle. En nuestro caso, tratamos de ir más allá de las representaciones y diferentes posturas surgidas alrededor de los niños deambulando por la urbe, como mencionamos, queremos saber qué es lo que ellos hacían en estos espacios, qué pensaban o qué demostraban con sus acciones. Estos niños y jóvenes rompieron con el ideal de infancia, mostraron un grado de autonomía que alarmó a las autoridades desde el momento que andaban solos en la ciudad sin la vigilancia de un adulto hasta su aceptación, en algunos casos, para seguir desempeñando sus actividades (Sosenski, 2013: 178).

Además, este deambular por las calles iba más allá de los alrededores de la urbe. Debido a la expansión de los medios de transporte y del ingenio de estos niños sabemos que su movilidad fue más amplia y que lograron trasladarse a otras partes de la República Mexicana. Este desplazamiento se debió tanto a la búsqueda de un trabajo, rencontrarse con sus familiares o simplemente por el sentido de aventura, como veremos más adelante. Los documentos analizados permiten diluir el porqué de su desplazamiento y la respuesta de las autoridades ante estas acciones. En este sentido, Yolanda Edith de Paz Trueba y Lucía Bracamonte observan también, para el caso de Buenos Aires, un desplazamiento geográfico de los niños y jóvenes por la provincia. Las autoras buscan "comprender cómo las acciones y las redes de sociabilidad de las comunidades estudiadas se articularon con los canales institucionales estatales y no estatales en el momento de atender la situación de carencias morales que afectaba a cierto sector de la infancia" y como al final la ayuda proporcionada por estas instituciones se convirtió en una estrategia de sobrevivencia para estos niños y sus familias, debido a que hicieron uso de los canales que se les ofrecía para "eludir dictámenes judiciales, refrendar decisiones propias tomas previamente y negociar resoluciones que convinieran a sus deseos e intereses" (Paz y Bracamonte, 2018: 201-205). Las ideas desarrolladas por las autoras nos permiten comparar las diferencias y semejanzas que hubo entre Buenos Aires y México para salvaguardar a la infancia.

El delegado investigador era el nombre que recibía la persona encargada de realizar el estudio social a los niños y jóvenes que ingresaban en el Tribunal, podemos señalar que son el antecedente de los trabajadores sociales. 


\section{Una ciudad ruidosa}

En los últimos años de la década de 1930, cuando el periodo del presidente Lázaro Cárdenas llegaba casi a su final, la ciudad y sus habitantes experimentaron una serie de trasformaciones que tuvo como fin último alcanzar la tan deseada modernidad y progreso del país. Por tal motivo se implementaron una serie de medidas para mejorar la ciudad y controlar a su población, con el mejoramiento de la ciudad se pretendió promover una imagen moderna, "higiénica y 'civilizada"'. Pero para lograr este objetivo se tenía que quitar de sus principales calles a la población que constantemente usaba estos lugares como espacios de trabajo, ocio y convivencia. De tal forma, que aquellos que deambularon por la ciudad, ya sea, laborando, paseando o mendigando se volvieron un problema para las autoridades capitalinas debido a que dañaban la imagen que se quería promover (Sosenski, 2013: 178-179).

La calle fue un espacio negociado entre los sectores populares y las autoridades. Para las primeras, era el espacio donde trabajaban, comían y, en muchos casos, dormían, era una extensión de su hogar, el lugar donde podían sociabilizar. En cambio, las autoridades buscaron mejorar la imagen de la ciudad, pero, también controlar a sus habitantes, se creía que con el control de la calle y de sus habitantes se podía evitar que se incubaran en la sociedad los vicios y depravaciones que rondaban en los "barrios populosos, oscuros y tétricos de la ciudad". Dentro de este panorama se puso especial atención a los niños que deambulaban por la ciudad" (Sosenski, 2013: 179, 180, 189).

El lograr apartar y controlar las actividades de los niños en la calle fue una lucha perdida. La realidad se impuso al discurso. En 1939, por ejemplo, el periódico El Nacional señalaba que a pesar de "las instancias de las autoridades y de las casas de beneficencia" para eliminar algunos males de la sociedad-vagancia, orfandad y pobreza-, existía "una población misteriosa que pulula por las calles y avenidas; andrajosa y egoísta; los limosneros." En esta llamada "Corte de los Milagros", como la prensa los denominó, también se incluyó a los niños y jóvenes de los barrios pobres de la ciudad. En su estudio sobre La mendicidad, Ramón Beteta señaló que de los 494 mendigos censados en 1930, el $12.5 \%$ tenía menos de veinte años; había 39 niños entre 0 y diez años y, 23 entre los diez y veinte (Beteta, 1931: 1213). Asimismo, en la nota periodística se señalaba que las "innumerables" disposiciones emitidas para desaparecer de "nuestra capital esta masa anónima" no habían logrado sus objetivos porque "los pilletes" escapaban "de las citadas casas de beneficencia para ambular nuevamente. Y hasta se ríen de sus benefactores y se ríen de todo". ${ }^{3}$

La población "anónima" que deambulaba y se apropiaba de las calles de la ciudad, no sólo era aquella que formaba parte de esta llamada "Corte de los Milagros", es decir, vagos y mendigos, también estaban incluidos los vendedores ambulantes. Las autoridades querían desaparecer a esta "Corte" no sólo porque dañaba la imagen de la capital, sino también, porque engañaban a los "incautos" con sus supuestas debilidades, deformidades o enfermedades. La misma nota periodística lo señalaba: "se ríen de sus benefactores", "se ríen de todo".

En el caso de los vendedores ambulantes, el problema iba en el mismo sentido, la imagen que daban al país y los problemas que causaban a los transeúntes. En los últimos años de la presidencia de Lázaro Cárdenas, la prensa informó de las medidas implementadas por las autoridades de la capital para resolver el problema del ambulantaje de "las principales calles del primer cuadro de la ciudad". ${ }^{4}$ Problema que no fue resuelto del todo, a pesar de que se mandaron a construir nuevos mercados para reubicar a los vendedores, los espacios eran insuficientes. De tal forma, el caos que causaban estos vendedores se sumaba al ruido y tráfico de los automóviles, de los vendedores de periódicos, de los boleros, de los billeteros, haciendo que: "Todo México es un 'Zoco" como "un campo de feria, donde se instalan insolentemente los individuos que comercian [con] los artículos más heterogéneos."

El aumento de las personas vendiendo u ofreciendo sus servicios en las calles o en las avenidas principales o fuera de los espacios públicos alarmó a las autoridades. A finales de los años treinta, a partir de los reportajes que aparecen en la prensa, ${ }^{6}$ se observa la preocupación de las autoridades de la ciudad para reglamentar estos espacios, tanto por el aspecto que daban como para prevenir la delincuencia. De esta manera, tanto los vendedores ambulantes como los billeteros, los muchachos "moscas" que tenían como objetivo poner orden, disciplina e higiene en la ciudad. Es en esta ciudad del ruido y del caos donde vivieron cientos de niños y jóvenes de los sectores populares de la ciudad de México, que al igual que los adultos se apropiaron de las calles y de sus espacios públicos.

Para finales de la década de 1930, seis ciudades del país presentaron un crecimiento importante, pero de esas seis, la ciudad de México registró un aumento de la población sumamente sobresaliente. En 1910, está ciudad registró a 471066 habitantes, pero para 1940 se censaron a 1559782 (Loyo, 2013: 239). Un factor que propició el aumento de la población en las urbes fue la migración. Las personas se instalaron en las ciudades para encontrar un mejor trabajo y poder tener un "mejor" tipo de vida, aunque la realidad a la que se enfrentaron distaba mucho de lo que esperaban.

Mario Barbosa señala que el aumento de la población no correspondió con un aumento de los espacios destinados para alojar a tanta población. Desde finales del porfiriato se realizaron obras de desagüe, drenaje y entubado, se limpiaron las calles con el fin de mejorar el aspecto de la ciudad, aparecieron nuevas colonias al poniente que fueron habitadas por las élites y la clase media. De esta manera abandonaron el centro para ubicarse en los nuevos fracciona-

\footnotetext{
"La Corte de los Milagros" en El Nacional, segunda sección, domingo 12 de febrero de 1939, pp. 1 y 2.

"Desaparecen los puestos" en El Excelsior, martes 10 de enero de 1939, pp. 1 y 6.

“Todo México es un 'Zoco"” en El Excelsior, segunda sección, jueves 3 de junio de 1940, pp. 1 y 3.

Para este texto nos centramos en los periódicos El Excelsior y El Nacional que se publicaron entre 1939 y 1940.

Eran niños y jóvenes que se subían en la parte trasera de los tranvías o automóviles y no pagaban el transporte.
} 
mientos, mientras que las viejas casonas deterioradas del centro se convirtieron en vecindades (Barbosa, 2003). Los cuartos de vecindades fueron una opción de alojamiento para las personas que provenían de otros estados, ya fuera porque tenían familiares o conocidos que los recibían o porque era una opción barata para quedarse. Por lo tanto, en estos cuartos vivían hacinados, sin agua o luz, porque quedaron en el olvido por las autoridades, quienes se concentraban en mejorar los nuevos espacios ocupados por la élite y la clase media. Con el correr del tiempo, las colonias olvidadas fueron consideradas por la prensa y las autoridades como lugares peligrosos, donde se podían encontrar a ladrones, prostitutas, mendigos o vagabundos.

De esta manera, la población, ya fuera residente o que provenía de otros estados del país, observó cambiar la ciudad. Ellos fueron testigos de los cambios, al ver como nuevos espacios eran ocupados para la construcción de residencias, parques o mercados y vieron como quedaban en el abandono y en el olvido las colonias populares del centro. También vivieron los cambios generados por los medios de transporte. En un principio, el transporte, como los tranvías eléctricos o el automóvil, hicieron fácil y rápido el traslado de los habitantes a cualquier parte del Distrito Federal y sus zonas aledañas. Pero con el tiempo, desplazarse por la ciudad se dificultaría cada vez más, debido al aumento de los automóviles, la prolongación de avenidas, la construcción de las primeras vías rápidas, de calzadas, etc. (Martínez, 2004: 394-409).

La apropiación de las calles por los sectores pobres de la ciudad fue una de las consecuencias de este aumento de la población y urbanización de la ciudad, como ya mencionamos al principio del texto. Las calles, como señala Mario Barbosa, fueron el espacio usado por trabajadores que no encontraron un empleo en los talleres, en las fábricas o comercios establecidos. De tal forma, este espacio permitió la subsistencia económica de estos trabajadores, personas que participaron "en la vida cotidiana con las posibilidades que les brinda cada momento y cada espacio social, y se adaptan a las circunstancias para lograr mínimas condiciones de sobrevivencia” (Barbosa, 2010: 1077-1080).

Si bien el trabajo de Mario Barbosa se centra en los trabajadores callejeros en las primeras décadas del siglo XX, considero que muchos de los planteamientos de este autor se ven reflejados en el caso de los niños y jóvenes que llegaron al Tribunal y sus familias (Barbosa, 2008). Ellos también quedaron insertos dentro de esta dinámica de la calle: de la apropiación, subsistencia y negociación. Pero a diferencia de las fuentes consultadas por el autor, los archivos del Tribunal nos permiten profundizar sobre la movilidad de estos niños y jóvenes por la ciudad y sus zonas colindantes. De acuerdo con los datos obtenidos de la revisión de 71 expedientes del Tribunal para Menores durante los años de 1939 y 1940, encontramos que ellos también se concentraron en las calles aledañas al primer cuadro de la ciudad, estuvieron alrededor de los mercados, de los parques, sitios concurridos como eran los cines o los teatros, en donde trabajaban y sociabilizaban con otros jóvenes y adultos.

\section{Movilidad de los niños y niñas en la ciudad}

En la actualidad, para algunos sectores de la población dejar salir solos a los niños a la calle es impensable, y mucho menos pensar en su desplazamiento a lugares más lejanos, pero para un sector de niños y jóvenes de los sectores pobres de la ciudad de México de finales de los años treinta, de acuerdo con los datos obtenidos, era algo común. Por ejemplo, si contrastamos la dirección de los niños y jóvenes que llegaron al Tribunal con el lugar de donde fueron detenidos, encontramos datos interesantes. La mayoría de ellos al cometer la infracción se encontraban lejos de sus hogares, algunos estaban a unas cuantas calles de sus casas, pero otros, se habían desplazados varios kilómetros.

De los 71 expedientes analizados entre 1939 y 1940, el 25\% no cuenta con esta información; pero alrededor del $21 \%$ había cometido la infracción cerca de su hogar; el 26.76\% provenía de otra delegación; el otro $26.76 \%$ no tenía hogar, es decir, en el momento de la detención, el niño o joven vivía en la calle. Los niños y jóvenes que se encontraban en la calle por lo regular se quedaban a dormir en los hoteles, en los mesones, en los dormitorios públicos, en los parques o las barricadas de los mercados. Algunas veces se encontraban solos o compartían el alojamiento con otros compañeros. Por ejemplo, Virginia vivía en un mesón con una señora, en donde fue abandonada, al parecer, por su madrastra. En este lugar trabajaba vendiendo café a los demás clientes. ${ }^{8}$ En cambio, Lorenzo tenía dos años aproximadamente de haber escapado de su hogar, se quedaba a dormir en los dormitorios públicos "tomando a veces sus alimentos ahí y otras en los mercados". ${ }^{9}$ De Alfonso se dijo que desde la muerte de su madre pululaba "en las calles y duerme en donde mejor puede, haciéndolo a últimas fechas en el kiosco de la Alameda de Tacubaya". ${ }^{10}$ Cada uno de los niños y jóvenes que fueron presentados al Tribunal se apropió de los diferentes espacios que la ciudad les proporcionaba para su diversión, resguardo y convivencia como mejor les convino. Estos espacios proporcionaron estrategias de sobrevivencia para aquellos que habían sido abandonados o que habían abandonado su hogar por diversas razones.

Antes de continuar, es pertinente señalar que la información que proporcionan los expedientes del Tribunal es muy rica y variada, pero el problema al que nos enfrentamos, en algunos casos, es que la información es incompleta. A veces se debe a que los niños y jóvenes se fugaban del Tribunal antes de concluir los exámenes o en todo caso daban información falsa o se negaban a hablar. Por tal motivo, la información que se presenta a continuación se realizó a partir de los datos que proporcionan esos 71 expedientes, que son los que corresponden a los años de 1939 y 1940 ,

\footnotetext{
Archivo General de la Nación (AGN), Consejo Tutelar para Menores (CTM), Caja 81, Exp. 20059, 1939.

AGN, CTM, Caja 87, Exp. 21064, 1940.
}

AGN, CTM, Caja 91, Exp. 21587, 1940. 
pero como no todos cuentan con la misma información, el número total de casos en las tablas que se presentan más adelante puede variar.

Por otro lado, se puede creer que los casos que se toman en cuenta para este trabajo son poco representativos, pero si se comparan con los datos que proporcionó el Departamento de Prevención en 1936 a partir de 4758 casos entre 1927 y 1931, veremos ciertas similitudes. Por ejemplo, la Tabla 1 muestra que las zonas de donde procedían los menores a la hora de su detención se ubican entre la segunda, tercera y novena delegación ${ }^{11}$ que coincide con los datos recabados por el Departamento de Prevención Social, en cuanto a las primeras dos delegaciones. Precisamente estas delegaciones eran aledañas al centro histórico de la ciudad, ver mapa 1. Algunos lugares conocidos de la segunda demarcación que podemos mencionar son: la colonia Obrera, la Merced, el parque Balbuena, el Hospital Juárez, el Hospicio de Niños, el mercado Jamaica. En la tercera demarcación se encontraba la colonia Morelos, el barrio de la Lagunilla, la Penitenciaría del Distrito Federal y la colonia Tepito.

Es en estas zonas donde niños y jóvenes comúnmente desempeñaban sus actividades laborales o de ocio. Por ejemplo, Manuel era vendedor ambulante en la Plaza Fray Bartolomé de las Casas; ${ }^{12}$ José vendía sopes y cargaba canastas en la Plaza de la Merced; ${ }^{13}$ Francisco vendía pescado en una cantina conocida como "La Orizabeña" que se ubicaba entre las calles Corregidora y Alhóndiga; ${ }^{14}$ y Marcelino vendía las plumas fuentes que robaba en el mercado Abelardo Rodríguez. ${ }^{15}$

La movilidad de estos niños y jóvenes se observa mucho mejor cuando eran aprehendidos en otras delegaciones. Por ejemplo, José vendía periódicos en San Juan de Letrán (primera delegación), después se iba a cantar a la puerta del cine Alameda pero cuando fue detenido se encontraba cerca de la Lagunilla (tercera delegación) ${ }^{16}$; Ricardo vivía en la calle Ezequiel Montes (séptima delegación) pero fue aprehendido en la quinta delegación; ${ }^{17}$ Facundo vivía en la calle Gabriel Mancera, en unos jacales que se encontraban en la décima delegación pero, fue detenido en la octava delegación cuando pretendía robar una bicicleta de alquiler. ${ }^{18} \mathrm{El}$ caso de Ángel es uno de los más ilustrativos en cuanto a este continuo desplazamiento. Él vivía a lado de sus abuelos, quienes vendían en la Lagunilla (quinta delegación), a veces pasaba unas temporadas con su mamá quien vivía en la calle Degollado (séptima delegación); pero cuando se escapó de su hogar se quedaba a pernoctar en el dormitorio público de Cuauhtemozinc (cuarta delegación) e iba a trabajar como canastero en el Mercado de la Merced (segunda delegación). ${ }^{19}$

Parece que para los niños y jóvenes analizados en este artículo no había barreras que impidieran su traslado por la ciudad a través de sus calles, parques, plazas, mercados, dormitorios públicos, etc. Estos lugares fueron espacios donde realizaron una diversidad de actividades adaptadas a sus necesidades. De tal forma que en estos lugares podían tanto trabajar como dormir o divertirse; podían ir solos o acompañados.

Tabla 1. Procedencia de los niños y las niñas de las diferentes delegaciones.

\begin{tabular}{|l|c|c|}
\hline \multicolumn{1}{|c|}{ Delegación de la que fueron aprehendidos } & Casos & Porcentaje \\
\hline 2a. Delegación & 12 & 16.9 \\
\hline Otros & 10 & 14 \\
\hline 3a. Delegación & 9 & 12.7 \\
\hline 9a. Delegación & 6 & 8.4 \\
\hline Penitenciaría & 6 & 8.4 \\
\hline 6a. Delegación & 5 & 7 \\
\hline 11a. Delegación & 5 & 7 \\
\hline 4a. Delegación & 4 & 5.6 \\
\hline 5a. Delegación & 4 & 5.6 \\
\hline 1a. Delegación & 3 & 4.2 \\
\hline 8a. Delegación & 3 & 4.2 \\
\hline 7a. Delegación & 2 & 2.8 \\
\hline 10a. Delegación & 1 & 1.4 \\
\hline 13a. Delegación & 1 & 1.4 \\
\hline
\end{tabular}

Fuente. Información obtenida a partir de los archivos del Tribunal para Menores, AGN, 1939-1940.

\footnotetext{
En este caso omitidos la segunda columna, "otros", debido a que no hay relación entre los 10 expedientes. Es decir, aquí se incluyeron los casos aislados de menores que fueron presentados por sus familiares, por la Procuraduría General de Justicia, de la escuela correccional, entre otros. AGN, CTM, Caja 31, Exp. 8925, 1934.

AGN, CTM, Caja 87, Exp. 21123, 1940.

AGN, CTM, Caja 91, Exp. 21694, 1940.

AGN, CTM, Caja 93, Exp. 21918, 1940.

AGN, CTM, Caja 91, Exp. 21608, 1940

AGN, CTM, Caja 91, Exp. 21635, 1940.

AGN, CTM, Caja 91, Exp. 21657, 1940.

AGN, CTM, Caja 81, Exp. 20048, 1939.
} 
Tabla 2. Procedencia de los menores infractores entre 1927-1931 de 4758 casos.

\begin{tabular}{|l|c|}
\hline \multicolumn{1}{|c|}{ Procedencia de los menores infractores entre 1927-1931 de 4758 casos } & Porcentaje \\
\hline Segunda Demarcación (Barrio de la Merced) & $14.21 \%$ \\
\hline Tercera Demarcación (Barrio de la Lagunilla) & $12.74 \%$ \\
\hline Cuarta Demarcación (Barrio de San Antonio Abad) & $11.20 \%$ \\
\hline Primera Demarcación (Barrios la Bolsa y El Carmen) & $9.02 \%$ \\
\hline Sexta Demarcación (Barrio de San Juan) & $8.14 \%$ \\
\hline A solicitud de particulares & $7.4 \%$ \\
\hline Quinta Demarcación (Barrio de Guerrero) & $7.37 \%$ \\
\hline Inspección General de Policía & $6.49 \%$ \\
\hline Delegaciones foráneas & $4.92 \%$ \\
\hline Octava Demarcación (Colonia Roma) & $4.89 \%$ \\
\hline Séptima Demarcación (Santa María la Ribera) & $4.57 \%$ \\
\hline Novena Demarcación (Tacuba) & $3.42 \%$ \\
\hline Décima Demarcación (Mixcoac) & $3.74 \%$ \\
\hline Onceava, Doceava y Treceava Demarcación (Tacubaya, Portales, Guadalupe) & $1.95 \%$ \\
\hline De la cárcel y del Hospital Juárez & $0.47 \%$ \\
\hline A solicitud de algunas instituciones & $0.33 \%$ \\
\hline Inspección de Sanidad & $0.12 \%$ \\
\hline
\end{tabular}

Fuente. Secretaría de Gobernación. Departamento de Prevención Social, Los Tribunales para Menores en el Distrito Federal y sus instituciones auxiliares, 1936, p. 118. ${ }^{20}$

Mapa. 1. Ciudad de México con sus delegaciones y colonias y directorio del plano. Año1930-1934, Mapoteca Manuel Orozco y Berra.

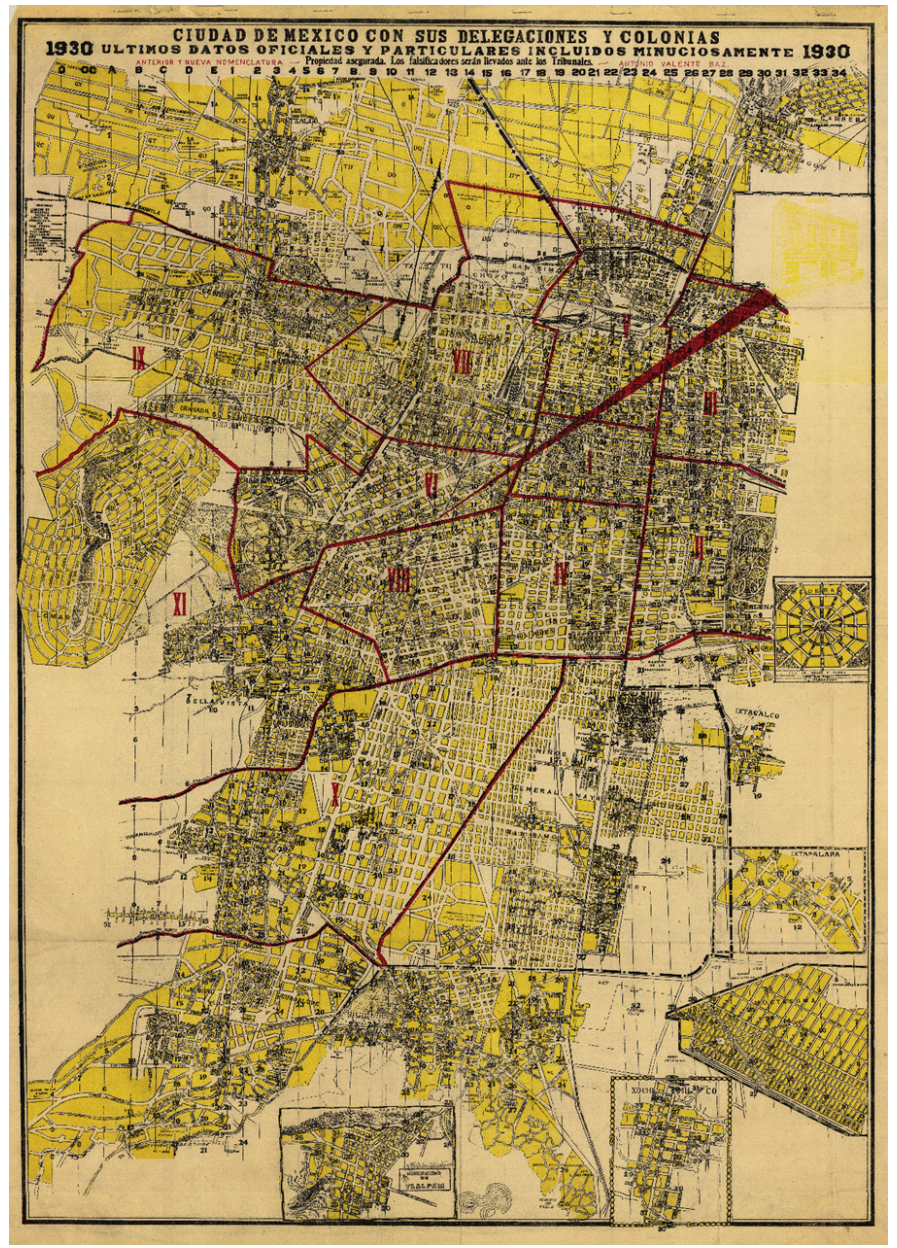

20 La tabla fue tomada tal y como aparece en la fuente citada. Lo mismo que el título. 
El ir y venir de los niños, jóvenes y adultos por la ciudad y sus zonas aledañas fue cada vez más fácil gracias a los medios de transportes. Éstos comenzaron a tener cambios significativos desde mediados del siglo XIX, un proceso que fue interrumpido por la revolución mexicana, pero continuaría con los gobiernos posrevolucionarios. Sergio Miranda señala que, entre 1858 y 1900, para el caso de Tacubaya los transportes experimentaron "notables e importantes cambios asociados al crecimiento de su población y urbanización". De tal manera, "los trenes de mulas fueron suplidos primero por los ferrocarriles de vapor, luego por los tranvías eléctricos y los vehículos automotores" (Miranda, 2007: 141), fue un cambio que los habitantes de la ciudad presenciaron y no dudaron en hacer uso de ellos. Por ejemplo, los niños y jóvenes podían irse de "moscas" en los ferrocarriles, tranvías o automóviles, es decir, sin pagar pasaje. Ramón Beteta en su libro Jarano, describe este tipo estrategias que realizó durante su infancia debido a la escasez económica. Beteta recordaba que para regresar a su casa, ubicada en Azcapotzalco desde la colonia Santa María, muchas veces tuvo que irse de "mosca":

Durante el día siempre había la esperanza de "mosquear" el tranvía, por lo menos una parte del trayecto. Esta era posible porque el remolque, que era de "segunda" y en el que yo viajaba, estaba generalmente pletórico y servía muy bien a mi propósito. Había que seguir cierta técnica, que con el tiempo llegué a perfeccionar: antes de abordar el tranvía, había que localizar al conductor. Si estaba cobrando los pasajes en la parte delantera, había que subirse por la plataforma posterior y permanecer en ella, vigilante, hasta que estuviera a punto de acercarse. Entonces, en la primera parada, o antes si se acercaba demasiado, había que bajar y, sin ser observado, ascender nuevamente por la parte delantera, subir a la plataforma, y de ser posible seguir al cobrador conforme avanzaba sin que se diera cuenta. Ya en la mitad del tranvía había la esperanza de que a su regreso no me considerara como recién entrado y pasara de largo sin exigir el boleto (Beteta, 1989: 73).

El irse de "mosca", como lo plantea Beteta, regularmente era por falta de dinero. Pero estos niños y jóvenes recurrían a esta estrategia no sólo para andar de un lugar a otro cerca de la ciudad de México, sino también para llegar a otras partes de la república mexicana. Por ejemplo, Heriberto, de 15 años, contó a los jueces que después de salir del Tribunal para Menores se fue a Aguascalientes "trampeando de mosca" en el ferrocarril, en donde estuvo por unos meses. ${ }^{21}$ Manuel, también de 15 años, dijo que al abandonar su hogar se vino a México con un amigo de "mosca" en los trenes. ${ }^{22}$ Justino dijo que se fue con un amigo a Cuernavaca y llegó hasta Acapulco, "dice que unas veces a pie y otras de 'mosca' en camiones de carga y que haciendo algunos trabajos". ${ }^{23}$ En este sentido, recordemos a Roberto, uno de los hijos de Sánchez entrevistado en su momento por al antropólogo norteamericano Óscar Lewis, que a la edad de 11 años, según recuerda se fue de casa para llegar a Veracruz:

Por principio de cuentas, caminé de aquí a los Reyes -caminar es mi vida-. Siempre me ha gustado el camino (...) El tren pasaba y yo podía haberme trepado - no tengo la anticuada mala costumbre de pagar pasaje- pero prefería caminar y admirar el paisaje. (...) Me fui, caminé, y ningún condenado carro me levantaba... ¡icómo me veían escuincle! Llegue hasta la Y donde corta la carretera a Texcoco, Puebla y Veracruz. Luego me levantó un camión, y me preguntaron: - ¿De dónde eres? (Lewis, 2012: 124).

Algunos de los niños o jóvenes que llegaron al Tribunal y que habían tenido la oportunidad de visitar otros estados de la República, ya sea pagando sus pasajes o como en los casos mencionados arriba, de "moscas", lo hacían con el fin de encontrar a sus familiares, de buscar trabajo o, como el caso de Roberto Sánchez, por diversión, por sentirse "como todos los aventureros" (Lewis, 2012: 125). De tal manera, estos niños y jóvenes se enfrentaron a las adversidades de la mejor forma posible, algunos de ellos se lanzaron a la búsqueda de nuevos espacios, inspirados por ese sentido "aventurero" o por la misma necesidad económica. Podían ir solos o acompañados, con o sin el permiso de sus familiares, huyendo de los malos tratos o por el afán de viajar y conocer nuevos lugares. Al final terminaron demostrando a las autoridades y demás personas que podían tomar sus propias decisiones.

\section{Hogar de los niños y jóvenes}

En cuanto al lugar donde vivían estos niños y jóvenes con sus familiares, también encontramos cierta similitud con las Tablas 1 y 2. De acuerdo con la Tabla 3, sus casas se encontraban ubicados entre la tercera, segunda y cuarta delegación. 
Tabla 3. Hogar de los menores por delegación.

\begin{tabular}{|c|c|c|}
\hline $\begin{array}{c}\text { Hogar de los niños y } \\
\text { jóvenes/Delegación }\end{array}$ & Casos & Porcentaje \\
\hline 3a. & 8 & 21 \\
\hline $2 \mathrm{a}$. & 6 & 15.8 \\
\hline 4a. & 5 & 13.2 \\
\hline $11 \mathrm{a}$. & 5 & 13.2 \\
\hline $7 \mathrm{a}$. & 4 & 10.5 \\
\hline 5a. & 3 & 7.8 \\
\hline 10a. & 3 & 7.8 \\
\hline 9a. & 2 & 5.2 \\
\hline 1a. & 1 & 2.6 \\
\hline 6a. & 1 & 2.6 \\
\hline
\end{tabular}

Fuente. Información obtenida a partir de los archivos del Tribunal para Menores, Archivo General de la Nación, 1939-1940.

La mayoría de ellos rentaban algún cuarto de vecindad, departamento o casa dentro de estas colonias, eran pocos los que contaban con vivienda propia. Para las autoridades, la prensa, los jueces y delegados investigadores del tribunal, estos lugares fueron considerados como insalubres e inmorales, "semilleros de vicios y comportamiento reprochables". Además, ligaron la pobreza material y la insalubridad con la criminalidad, como lo fue el caso de Tepito, que desde el siglo XIX y hasta nuestros días, ha sido visualizado como un "barrio violento y peligroso, sucio refugio de personas de dudosa reputación" (Aréchiga, 2004: 271, 285). Y precisamente, el barrio de Tepito estaba ubicado en la tercera delegación y que de acuerdo con la Tabla 3, el 21\% de los hogares de estos niños y jóvenes estaba ahí.

Por ejemplo, en el caso de Ramón que vivía en Tepito se dijo que a pesar de que su "vecindad tiene servicios sanitarios y se encuentra, aunque no en condiciones completamente favorables sí aceptables” pero, el barrio "es sumamente sucio, populoso, lleno de pulquerías, cantinas y puestos de la peor categoría. Frecuentando gente del hampa." ${ }^{24}$ Por otro lado, en el caso de Isaías que vivía con su familia en la calle Carpintería, también en la tercera delegación, se mencionó que "no hay servicio de agua, la madre acarrea de la vecindad de al lado en donde también están los excusados para toda la cuadra. Hay completo desaseo tanto en la habitación como en el barrio en general." 25 Del hogar de Jesús se dijo que "la vecindad que habitan tiene cerca de 300 viviendas, se alquila el pedazo de terreno y si está en condiciones se construye el huacal... tienen amigos de la vecindad y del barrio, vagos y malvivientes". El hogar de Jesús se encontraba sobre la calle Azucena en la cuarta demarcación. ${ }^{26}$

Este tipo de comentarios se pueden encontrar en varios expedientes durante la década de los veinte y treinta. Opiniones que reflejan la discriminación de las autoridades hacia los sectores pobres de la ciudad, pero también expresan la situación social de estos niños y jóvenes. Un poco menos de la mitad de los que ingresaron al Tribunal provenían de alguna parte de la República, como ya mencionamos, la migración fue un fenómeno importante en el crecimiento de las ciudades. Al llegar a la ciudad tuvieron que adaptarse a lo que esta les ofrecía y, uno de los principales problemas a los que se enfrentaron fue a la escasez de vivienda. De tal forma, algunos se quedaron a vivir en las vecindades, donde podían tener amigos o familiares, otros se quedaron en los hoteles, en los mesones o hicieron uso de los dormitorios públicos. Por tal motivo, en algunos de estos cuartos de vecindad se podían alojar hasta más de diez personas, provocando el hacinamiento y la falta de higiene que tanto preocupaba a las autoridades desde finales del siglo XIX.

Además de los factores antes mencionados, las familias también se enfrentaban a la falta de los servicios públicos, como el agua, la luz, la pavimentación, el drenaje, etc. De tal forma que las condiciones en que vivían estos niños y jóvenes con sus familias fueron rechazadas por parte de las autoridades. Lo interesante de los casos analizados es que el hogar ocupó un lugar secundario en su vida. Recordemos que, de los expedientes analizados, el 26.76\% de ellos procedía de una delegación distinta de su hogar y, un porcentaje igual equivalía a los niños y jóvenes que vivían en la calle.

\section{Niños y jóvenes trabajando}

De los 71 expedientes analizados sólo tres niños se dedicaban al estudio en el momento de su detención, dos de ellos complementaban su tiempo con algún trabajo. Pero, la mayoría de ellos trabajaba y sólo habían cursado algunos años de la escuela elemental. De acuerdo con la tabla 4, el 26.6\% había trabajado en algún taller como aprendiz de un oficio (zapatero, panadero, yesero, etc.,); el 23.4\% había trabajado en los mercados, aquí incluimos a los canasteros y 
a los que tenían algún puesto fijo; por otro lado, otro 23.4\% había trabajado en la calle (vendedores de periódicos, de billetes de lotería, boleros, cuidadores de carros, chicos que cantaban en las calles o vecindades, etc.); y un $18.8 \%$ se había dedicado al ambulantaje, en este caso nos referimos a los niños y jóvenes que vendían sus productos en puestos semifijos o que tenían que desplazarse para vender sus productos, como los vendedores de frutas, verduras o carnes. Sólo el 7.8\% había trabajado en alguna fábrica como obrero.

Tabla 4. Lugar de trabajo de los niños y jóvenes.

\begin{tabular}{|l|c|c|}
\hline Lugar de trabajo de los niños y jóvenes & Casos & Porcentaje \\
\hline Talleres & 17 & 26.6 \\
\hline Mercados & 15 & 23.4 \\
\hline Calle & 15 & 23.4 \\
\hline Vendedor ambulante & 12 & 18.8 \\
\hline Fábricas & 5 & 7.8 \\
\hline Casas & 5 & 7.8 \\
\hline Escuela & 3 & 4.6 \\
\hline Cine & 2 & 3.1 \\
\hline Chofer & 2 & 3.1 \\
\hline
\end{tabular}

Fuente. Información obtenida a partir de los archivos del Tribunal para Menores, Archivo General de la Nación, 1939-1940.

Los trabajos que los niños y jóvenes desempeñaron en la ciudad, como observamos en la Tabla 4, eran variados. La mayoría de las veces dependiendo de su situación social, realizaban varias actividades al día y cuando no tenían suficiente dinero para comer, podían pedir limosna o en todo caso recurrían al robo, debido a que los lugares en donde ejercían sus actividades eran espacios propicios para cometer alguna infracción. Prospero "hacia mandados en la vecindad" y "ayudaba en el cine Tintan con el aseo y limpiar calzado"27; Lorenzo trabajaba como canastero y bolero $\mathrm{y}$, algunas veces imploraba la caridad pública; ${ }^{28}$ Manuel pedía limosna y cantaba, vendía periódicos y trabajaba como de canastero en la Lagunilla, con sus ganancias comía y se compraba ropa. ${ }^{29}$ A partir de estas actividades ayudaron a sus familias o a subsistir por sí mismos

Al observar sus ocupaciones podemos entender su movilidad por la ciudad, buscaban espacios propicios para la venta o el entretenimiento, al igual que los adultos. Las actividades que realizaban podían ser en espacios cerrados, pero la mayoría de ellas eran ejecutadas en la calle, de tal forma que, para las autoridades y la prensa, estos niños y jóvenes pasaron a formar parte de esa famosa "corte de los milagros" que tanto sorprendía y atemorizaba a las autoridades.

Otro elemento relevante en estos casos es la ausencia de las niñas y las jóvenes en los espacios públicos, Susana Sosenski señala que los niños tenían más oportunidades de desempeñar diversas actividades que las niñas, quienes estaban destinadas por lo general al "ámbito privado", es decir, el hogar. El trabajo que desempeñaban las niñas y las jóvenes por lo regular “era un trabajo 'invisible’ que escapaba del ojo público, en tanto pertenece al ámbito privado y familiar se encontraba ajeno a la mirada de la policía, del estado”, etc. (Sosenski, 2007). A ellas las encontramos, en la mayoría de los casos de las niñas o jóvenes infractoras, trabajando como domésticas en casas particulares y, sólo tenemos noticias de su presencia cuando eran acusadas por sus patrones de robo o eran objeto de abuso (violación, estupro o rapto) o por azares del destino.

En nuestro caso, de los 71 expedientes analizados sólo tenemos el registro de ocho mujeres, de esas ocho, cinco llegaron a trabajar como domésticas. Asimismo, cinco de ellas provenían de otros estados de la república: Michoacán, Oaxaca y Yucatán. María Eugenia Sánchez señala que los flujos migratorios fueron constantes desde el siglo XIX pero que entre 1930 y 1940 hubo un ascenso, de tal forma las mujeres provenientes de otros estados solían "incorporarse al trabajo doméstico," como el caso de estas jovencitas (Sánchez, 2014: 89). También se dedicaban a vender en los mercados o fondas. Pero pareciera que para ellas las calles estaban doblemente prohibidas, primero, por ser menores de edad y, segundo por ser mujeres. Es decir, el discurso expuesto por la prensa y las autoridades, la calle era un peligro para los niños y jóvenes porque sus espacios los podía tentar para cometer alguna infracción, los exponía a que convivieron con mendigos, vagabundos, rateros, y en el caso de las niñas y jovencitas podían ser expuestas con mujeres de la "vida galante" que las podían corromper y seguir por ese camino. Además, se exponían a que les pasará algo o simplemente que su reputación quedará entre dicho por andar solas por la calle.

En este sentido, uno de los objetivos del Tribunal para Menores era prevenir o corregir que niños y jóvenes que pisaban la institución continuarán su camino hacia la delincuencia. De esta manera, las autoridades del Tribunal habían 
establecido las pautas y paradigmas que debían adoptar, así que de los varones se esperaba que fueran trabajadores, estudiosos (si se podía) y responsables de sus familiares. En cambio, las mujeres tenían que ser "castas", mostrar agrado por las labores propias de su sexo, dedicadas al hogar; si tenían que trabajar, que fuera en espacios "decentes", no debían andar solas a altas horas de la noche en la calle o estar en espacios "inapropiados" para ellas. Por eso decimos que para ellas la calle estaba doblemente prohibida, un niño o joven podía andar sólo a altas horas de la noche y pasar desapercibido por las autoridades, pero no era lo mismo para una niña o una jovencita.

Las niñas y las jóvenes que llegaron al Tribunal o que de cierta forma estuvieron involucradas con la institución, se debió principalmente a casos relacionados con "la moralidad pública y el resguardo social". "Fueron llevadas por no actuar como lo exigía la moral de la época; entonces no era 'bien visto' que las mujeres asistieran a los bailes públicos o 'Dancing', ni que anduvieran solas en la calle de noche"; sus delitos "estaban en el espacio de lo moral y lo inmoral de sus relaciones con el sexo opuesto". Las autoridades consideraban que su destino eran convertirse en "madres y esposas responsables de la moral y educación de los niños y jóvenes". Por lo tanto, si su comportamiento era diferente al esperado eran criminalizadas (Sánchez, M., 1997: 165-166).

\section{La calle: entre el trabajo, el ocio y la criminalidad}

De acuerdo con nuestra información, más del $60 \%$ de los casos aquí analizados realizaron sus actividades laborales en espacios concurridos o en la calle, como ya hemos mencionado. De tal forma que ellos también se vieron afectados directamente con las reglamentaciones y el control que las autoridades trataron de implementar en las principales calles de la ciudad.

Durante 1939, como mencionamos al inicio del texto, las autoridades trataron de desalojar a los vendedores fijos y semifijos del centro de la ciudad. En enero de ese año, el periódico El Excelsior publicaba “una vez más" el desalojo de los comerciantes del primer cuadro de la ciudad debido a que "obstruían las banquetas de la Plaza de la Constitución" ${ }^{30}$ Para ello se inició una razzia de vendedores, desde temprano "grupos de gendarmes y vigilantes" impidieron la instalación de "dulceros, vendedores de juguetes, chucherías y otros objetos". El disgusto se acrecentó entre los comerciantes y las autoridades cuando los policías dejaron poner sus puestos a los vendedores que contaban con licencia, por tal motivo se dijo que se trataría de "cancelar dichas licencias" debido a que el principal objetivo era "despejar todo el primer cuadro de la metrópoli, quitándole el aspecto de "zoco" oriental". ${ }^{31}$ Tres meses después, el mismo periódico publicaba que Raúl Castellanos, jefe del Departamento Central, había "dictado urgentemente contraorden" "puesto que con semejante orden resultaban afectados no menos de 24000 comerciantes en pequeño". 32 Al final las autoridades aceptaban que estos trabajos eran indispensables para la subsistencia económica de una buena parte de la población pobre de la ciudad.

A pesar de las contraordenes, el interés de las autoridades por controlar y limpiar las calles no mermo, sino que otros actores sociales fueron incluidos o retomados. Desde los años treinta se habían realizado las razzias contra los "vagos y malvivientes" y antes de eso se había intentado controlar el trabajo de los boleros y vendedores de periódicos en las calles (Gutiérrez y Gantús, 2013; Guerrero, 2010). En su momento se hizo una "limpia de delincuentes" destinada a poner fin al robo de automóviles, se dijo que "independientemente de la razzia de vagos y malvivientes, la policía capitalina" aprehendería a "los espontáneos cuidadores de coches que pululan a las puertas de cines y restaurantes". ${ }^{33}$ Para las autoridades, la línea entre este tipo de oficios desempeñados en la calle (canasteros, vendedores de periódicos, boleros, cuidadores de coche, vendedores ambulantes, etc.) y la delincuencia era muy fina. Por ejemplo, en el caso de los voceadores de periódicos, Florencia Gutiérrez y Fausta Gantús señalan que la regulación de este trabajo "estaba impregnada de prejuicios, de una carga moral que levantaba sobre estos niños y jóvenes la permanente sospechosa de la trasgresión, el escándalo y la vagancia” (Gutiérrez y Gantús, 2013: 97).

Lo que observamos en las páginas de los periódicos El Excelsior, El Universal y El Nacional con relación a la infancia callejera, es una preocupación por controlar y sacar de las calles a estos niños. Las autoridades consideraban que los espacios en donde realizaban sus actividades ejercían una influencia "nociva en su comportamiento" que los orillaba a la delincuencia. Este tipo de preocupación se vio manifestada en el control de sus actividades laborales, pero también de sus acciones cotidianas. En líneas arriba, retomamos lo que significó para Ramón Beteta, Roberto Sánchez y otros menores el irse de "mosca" en los tranvías, trenes o automóviles para desplazarse por la ciudad o el país. Era una actividad que les permitía viajar sin preocuparse por la cuestión económica, pero para las autoridades de la ciudad significó el espacio donde los niños podían cometer travesuras, poner en riesgo su vida, pero sobre todo, la realización de actos delictivos. Por eso no fue extraño que en mayo de 1939 se comunicara a través de la prensa que los muchachos "moscas" serían perseguidos porque "acostumbran a subirse a los tranvías para robar los sombreros de los pasajeros”. En el mismo artículo se señalaba que habían sido detenidos 151 individuos, los que habían sido llevados a "las correspondientes delegaciones para ser consignados al Tribunal para Menores" y que "en caso de que esos chiquillos sean puestos en libertad, la campaña proseguirá". ${ }^{34}$ En este caso, pareciera que no importaba

\footnotetext{
"Desaparecen los puestos" en El Excelsior, martes 10 de enero de 1939, pp. 1 y 6.

"Hubo escenas de disgusto en el Zócalo" en El Excelsior, segunda sección, miércoles 11 de enero de 1939 , pp. 1 y 6.

"Los vendedores ambulantes no serán retirados" en El Excélsior, segunda edición, sábado 29 de abril 1939, p. 8.

"Limpia de delincuentes habrá en la ciudad” en El Excelsior, segunda sección, jueves 16 de febrero de 1939 , pp. 1 y 6.

"Muchachos 'mosca' que se perseguirán” en El Excelsior, segunda edición, miércoles 10 de mayo de 1939, p. 1.
} 
si los niños o jóvenes habían o no cometido una infracción, lo que importaba era desalentarlos a continuar con esta costumbre, porque una vez que cayeran en manos del Tribunal se corría el riesgo -después de haberse practicado los exámenes correspondientes- que fueran retirados de su hogar y colocados en algún otro establecimiento de la institución. En este sentido, la noticia publicada en la prensa sirvió para alertar a los padres de lo que les podía pasar a sus hijos si hacían mal uso de los espacios públicos.

Pero a pesar de las medidas impuestas por las autoridades, los niños y jóvenes siguieron laborando en la calle. Además, el trabajo que desempeñaban no impedía que realizaran otras actividades. De acuerdo con la Tabla 5, la principal recreación de los menores fue el cine. Susana Sosenski señala que "los niños fueron atraídos por el cine como las abejas por la miel" (Sosenski, 2006: 42), sin importar los debates que hubo alrededor de este tema a principios de la década de los veinte, para los años treinta seguía siendo una de las principales actividades de recreación que se combinó con otras. Por ejemplo, a Roberto le gustaba el cine, el box, la natación y el billar5; a Ofelia le gustaban los bailes públicos, el cine e ir a las carpas ${ }^{36}$, Rafael era "afecto a toda clase de deportes y concurría al cine con frecuencia" y le gustaban los bailes ${ }^{37}$; Justino también concurría al cine y con frecuencia iba al teatro, le gustaba el "género de revistas", el box y las luchas ${ }^{38}$, María del Carmen se divertía en el cine, yendo a pasear a Xochimilco "o a los parques de la ciudad.” 39

Tabla 5. Diversiones e intereses manifestados por los niños y las niñas ingresadas al Tribunal.

\begin{tabular}{|l|c|c|}
\hline \multicolumn{1}{|c|}{ Diversiones } & $\mathbf{N}^{\mathbf{0}}$. Casos & Porcentaje \\
\hline Cine & 43 & 84.31 \\
\hline Deportes & 10 & 19.6 \\
\hline Paseos & 9 & 17.6 \\
\hline Carpas o teatro & 8 & 15.6 \\
\hline Billares & 8 & 15.6 \\
\hline Boxeo o luchas & 7 & 13.7 \\
\hline Bailes & 7 & 13.7 \\
\hline Lectura & 4 & 7.8 \\
\hline Corrida de toros & 1 & 1.9 \\
\hline
\end{tabular}

Fuente. Información obtenida a partir de los archivos del Tribunal para Menores, Archivo General de la Nación, 1939-1940.

Estos niños y jóvenes se apropiaron de los espacios públicos como cualquier otro niño o joven de la ciudad de México, sin importar a que sector pertenecían. De hecho, las mismas autoridades propiciaron la reunión de niños en estos espacios públicos. Por ejemplo, el periódico El Nacional redactó que a principios de enero de 1939 se realizaría un "gran función del 'Fernandi' a niños pobres, en donde se esperaba que asistieran de "dos a tres mil niños" para ello se habían regalado boletos a los "niños cuyas necesidades están a la vista". ${ }^{40}$

Las festividades que se realizaban en esta época del año también incluyeron a otros sectores de la sociedad. Unos días antes, El Excelsior anunció la carrera de "autos, bicicletas, patines del diablo y cochecitos" que se realizaría en Chapultepec con motivo de los regalos que estos niños recibirían de los "Santos Reyes". ${ }^{41}$ Es evidente que en la carrera participarían niños pertenecientes a los sectores medios y altos de la sociedad, a diferencia de los niños de los sectores populares, estos niños encontrarían sus regalos en la madrugada del 6 de enero. A los demás niños les tocaba esperar que las autoridades hicieran alarde de su nobleza para recibir obsequios, como lo fue la fiesta organizada por el Club Internacional de Mujeres realizada en el Parque Lira, en Tacubaya para los "niños enfermos mentales". En dicho evento se repartieron "juguetes, ropa y dulces". Al final de la nota se decía "nos vamos pensando en el que el Club Internacional de Mujeres, ha elegido bien el sitio en donde ejercer la caridad. Quizás de estos pobrecillos, nadie se había acordado" "y un grupo de señoras tuvo el caritativo pensamiento de traerles un día de alegría" ${ }^{42}$

La realización de estas festividades con fines caritativos representa a la niñez de los sectores populares como una infancia desdichada, triste e infeliz y, que sólo a través de las acciones de otras personas conocen un poco de "felicidad y cariño”. Pero en verdad ¿cuántos de estos niños y niñas sabían de la existencia de los Reyes Magos?, ¿cuántos de ellos se ilusionaban o desilusionaban con los regalos otorgados ese día? El objetivo del texto no es responder estas preguntas, sino mostrar las "diferentes infancias" que se dieron en estos años, del ir y venir de los menores en la ciudad de México,

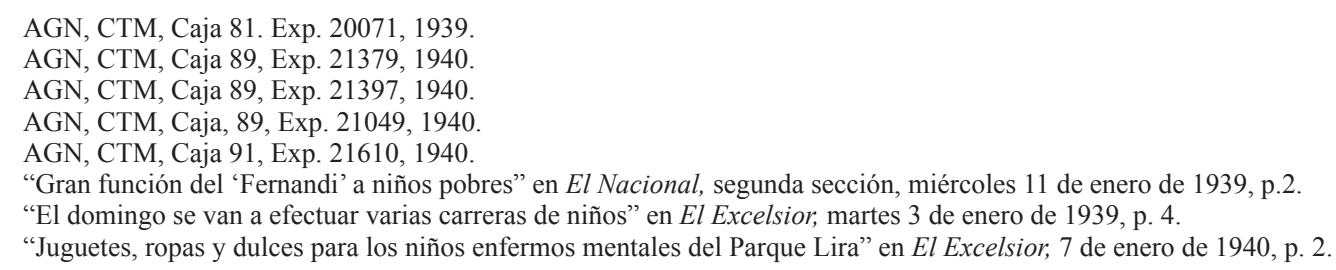


de mostrar un poco de su cotidianidad en una ciudad en crecimiento. A pesar de la criminalización y discriminación de los niños de los sectores pobres, las autoridades posrevolucionarias se preocuparon por ellos, de darles cobijo y comida. Al respecto, El Nacional señalaba que, en el mes de febrero de 1939, Silvestre Guerrero, Secretario de Asistencia Pública realizaría una "labor social en favor de la niñez" para "proteger a los niños desheredados, ya que se piensa que son niños los que merecen toda la atención oficial, para evitar que 'la corte de los milagros' tenga más prosélitos". ${ }^{43}$

\section{Reflexiones finales}

Desde las primeras décadas del siglo XX, la ciudad de México sufrió una serie de cambios acaecidos del movimiento armado y de procesos que se venían gestando desde décadas anteriores, como fue la migración. La población de la ciudad tuvo que adaptarse a estos cambios, que fueron tanto físicos como políticos, sociales y económicos. Dentro de este proceso de adaptación se dio la apropiación y negociación de los espacios públicos entre las autoridades y la población. Los niños de los sectores populares no fueron ajenos a estos procesos, como hemos visto en el texto, ellos también negociaron y reconfiguraron estos espacios, se adaptaron al momento que les tocó vivir. Vivieron su infancia a partir de lo que la ciudad les ofrecía, una infancia donde no había límites entre el trabajo y la diversión, mezclaron sus actividades para poder subsistir y, en todo caso, ayudar a sus familiares.

Al principio del texto señalábamos los vacíos historiográficos que hay sobre la historia de la infancia debido a la falta de fuentes y como los trabajos que encontramos están enfocados a determinados temas y periodos. Pero también mencionamos que esto no ha sido un obstáculo para seguir buscando y mirar con otros ojos las fuentes existentes, y esto fue lo que sucedió en nuestro caso. Al leer los expedientes de los niños y jóvenes del Tribunal para Menores, una de las cosas que nos sorprendió fue su desplazamiento por la ciudad y el uso que le daban, observamos que para ellos no había límites entre lo que se podía hacer o no en la ciudad y sin saberlo rompieron con el "ideal" de infancia de la época, y mostraron una verdad más cruda de lo que estaba pasando a su alrededor. Estaban acostumbrados a andar en la calle porque desde pequeños acompañaban a sus familiares a realizar todo tipo de actividades, las cuales después pasaban a desempeñar solos. Para ellos, andar solos o en la noche no representaba un peligro porque conocían los lugares a donde podían ir de acuerdo con sus necesidades, si necesitaban dinero se trasladaban a los mercados para cargar las compras de las señoras a cambio de unos cuantos centavos, podían pedir limosna a las afueras de los cines, de los teatros o en las aceras, cantaban en las calles o dentro de las vecindades. Para los más osados y que huían de sus hogares por el mal trato que recibían por sus familiares o que no les quedaba de otra porque habían sido abandonados, podían dormir en los dormitorios públicos de la ciudad o si al final del día les había ido bien, podían juntarse con otros amigos y alquilar un cuarto de hotel.

El grado de independencia que manifestaban y que tanto preocupó a las autoridades, lo obtuvieron sin haberlo pedido y al final se terminaron acostumbrando a vivir por sí mismos. Por eso, cuando las autoridades intentaron encauzarlos por el "buen" camino ellos se resistieron, así que terminaron por fugarse del Tribunal o de las instituciones a las que fueron enviados para corregir su comportamiento y de sus hogares también huyeron. Esa libertad a la que estaban acostumbrados les permitió que se trasladaran a otras partes de la ciudad o en todo caso del país.

Las experiencias descritas por los niños y jóvenes que pisaron el Tribunal y los artículos publicados en la prensa demuestran que hubo diferentes formas de vivir la infancia. La prensa idealizaba una infancia feliz, de niños, niñas y jóvenes bajo el resguardo de una familia, de una casa; que asistían a la escuela y recibían sus regalos en los días correspondientes como sus cumpleaños o festividades navideñas. Estos niños y jóvenes se comportaban de forma correcta, obedecían a sus padres, salían a la calle acompañados y hacían uso de los espacios públicos de forma correcta. De tal forma, para ellos era inconcebible que los niños de las clases pobres se comportaran de forma distinta, para la prensa y las autoridades fue fácil culpar a los padres de las acciones de sus hijos, fueron pocos los que vieron la situación de estas familias con otros ojos. Al final era más fácil criminalizarlos y desdeñar las actividades que desarrollaban, de crear instituciones para paliar la pobreza o el abandono en que se encontraban. Pero los estudios recientes demuestran que las familias de estos niños y jóvenes utilizaron las instituciones a su conveniencia, y a pesar de su corta edad, ellos participaron también en este proceso. Fueron niños y jóvenes que se enfrentaron a la vida que les toco vivir de la mejor forma, al mismo tiempo que trabajaban, buscaban actividades para divertirse y convivir con otros niños y jóvenes.

\section{Referencias bibliográficas}

Aréchiga, E. (2004). La formación de un barrio marginal: Tepito entre 1868 y 1929. En C. Collado (Coord.), Miradas recurrentes I. la ciudad de México en los siglos XIXy XX (pp. 271-293). México: Instituto Mora/Universidad Autónoma Metropolitana Azcapotzalco.

Análisis comparativo de la población de la ciudad de México según censos de población, 1930-1950-1970 (en línea).

http://www.igeograf.unam.mx/sigg/utilidades/docs/pdfs/publicaciones/inves_geo/boletines/4/bol4_art41.pdf, acceso 9 marzo de 2017.

43 “Labor de servicio social en favor de la niñez" en El Nacional, segunda sección, domingo 5 de febrero de 1939, pp. 1 y 3. 
Barbosa, M. (2003). "Insalubres e inmolares": alojamientos temporales en la ciudad de México, 1900-1920. Scripta Nova. Revista Electrónica de Geografía y ciencias sociales. Universidad de Barcelona. Vol. VII. Núm. 146, agosto 2003 (en línea). http://www.ub.edu/geocrit/sn/sn-146(053).htm, acceso 9 marzo de 2018.

Barbosa, M. (2008). El trabajo en las calles. Subsistencia y negociación política en la ciudad de México a comienzos del siglo XX. México: El Colegio de México/Universidad Autónoma Metropolitana-Cuajimalpa.

Barbosa, M. (2010). Trabajadores en las calles de la ciudad de México: subsistencia, negociación y pobreza urbana en tiempos de la Revolución. Historia Mexicana, LX (2), 1077-1080.

Beteta, R. (1931). La mendicidad en México. México: Beneficencia Pública en el Distrito Federal.

Beteta, R. (1989). Jarano. México: Fondo de Cultura Económica.

Cruz, M. S. (2004). El poblamiento popular en la ciudad de México en la primera mitad del siglo XX. En C. Collado (Coord.), Miradas recurrentes I. la ciudad de México en los siglos XIX y XX (pp. 376-393). México: Instituto Mora/ Universidad Autónoma Metropolitana Azcapotzalco.

Del Castillo, A. (1998). Entre la criminalidad y el orden cívico: imágenes y representaciones de la niñez durante el porfiriato. Historia Mexicana, 48(2), 277-320.

Farge, A. (1991). La atracción del archivo. España: Edicions Alfons El Magnànim. Institució Valenciana D’Estudis I Investigació.

Gutiérrez, F., F. Gantús (2013). Los pequeños voceadores: prácticas laborales, censura y representaciones a finales del siglo XIX. En C. Illades y M. Barbosa, Los trabajadores de la ciudad de México 1860-1950. Textos en homenaje a Clara E. Lida (pp. 81-115). México: El Colegio de México/Universidad Autónoma Metropolitana-Cuajimalpa.

Lewis, Ó. (2012). Los hijos de Sánchez. Una muerte en la familia Sánchez. México: Fondo de Cultura Económica.

Loyo, E. (2013). El México revolucionario (1910-1940). En P. Escalante et. al., La vida cotidiana en México (pp. 173239). México: El Colegio de México.

Martínez O. (2004). Los efectos de las vías de comunicación en la fragmentación de los espacios físicos y sociales de la ciudad de México. En C. Collado (Coord.), Miradas recurrentes I. la ciudad de México en los siglos XIX y XX (pp. 394-409). México: Instituto Mora/Universidad Autónoma Metropolitana Azcapotzalco.

Miranda, S. (2007). Tacubaya, de suburbio veraniego a ciudad. México: Universidad Nacional Autónoma de México/ Instituto de Investigaciones Históricas.

Osta, M. L., Espiga S. (2017). La infancia sin historia: propuestas para analizar y pensar un discurso historiográfico. Página de educación, Vol. 10, Núm. 10, 111-126.

Paz, Y., Bracamonte L. (2018). Movilidad y circulación geográfica. Niños y jóvenes en la provincia de Buenos Aires (Argentina), 1880-1919. HISTOReLO. Revista de Historia Regional y Local. Vol. 10, julio-diciembre de 2018.

Reyes, Ó. (2004). La apropiación cultural de la ciudad por la niñez tapatía en los albores del silo XX. En L. Herrera (coord.), Estudios sociales sobre la infancia en México (pp. 119-158). México: Benemérita Universidad Autónoma de Puebla.

Sánchez, M. E (2013). Menores en la prostitución clandestina: entre la sanidad y la protección. Ciudad de México (19301940) (pp. 195-222). En Sánchez M. E., Salazar D. (Coords.), Los niños: El hogar y la calle. México. Instituto Nacional de Antropología e Historia.

Sánchez, M. E. (2014). Menores transgresores, derecho penal y Tribunal para Menores. Antropología. Boletín Oficial del Instituto Nacional de Antropología e Historia, mayo-agosto, 86-101.

Sánchez, H. M. (1997). Las fronteras de la trasgresión. La formación del Tribunal para Menores Infractores de la ciudad de México, 1926-1931. México: Tesis para maestría en Historia y etnohistoria, Escuela Nacional de Antropología e Historia.

Sosenski, S. (2006). Diversiones malsanas: el cine y la infancia en la ciudad de México en la década de 1920. Secuencia. Revista de historia y ciencias sociales, 66, 35-64.

Sosenski, S. (2007). Lejos del ojo público: Las servidoras domésticas infantiles en la ciudad de México, 1917-1934, en ponencia presentada en el IV Coloquio de historia de las mujeres y de género en México.

Sosenski, S. (2010). El trabajo infantil en la ciudad de México (1920-1934). México: El Colegio de México.

Sosenski, S. (2013). La calle y los niños. Una mirada a las representaciones y experiencias infantiles en la ciudad de México durante la posrevolución. En E. Sánchez, D. Salazar (Coords.), Los niños. El hogar y la calle (pp. 177-193) México: Instituto Nacional de Antropología e Historia.

Sosenski, S., Jackson, E. (2012). Nuevas miradas a la historia de la infancia en América Latina. Entre prácticas y representaciones. México: Universidad Nacional Autónoma de México/ Instituto de Investigaciones Históricas.

\section{Hemeroteca}

El Excelsior (1939-1940).

El Universal (1939-1940).

El Nacional (1939-1940).

\section{Archivo}

Archivo del Tribunal para Menores Infractores del Distrito Federal, Archivo General de la Nación, 1939-1940. 
